\title{
Study of electrocution deaths in Puducherry
}

\author{
Fremingston Marak ${ }^{1, *}$, Mima Maychet B. Sangma ${ }^{2}$, Ganesh Kumar ${ }^{3}$ \\ ${ }^{\mathbf{1}}$ Associate Professor \& HOD, ${ }^{3}$ Tutor, Dept. of Forensic Medicine, ${ }^{\mathbf{2}}$ Associate Professor, Dept. of General Surgery, Indira Gandhi \\ Medical College \& Research Institute, Puducherry \\ *Corresponding Author: \\ Email: fkston@gmail.com
}

\begin{abstract}
Introduction: Electrocution deaths are not uncommon and most of the cases are accidental in nature. The study has been carried out to find out the incidence of electrocution deaths in Puducherry. Only few studies were done on electrocution deaths in Puducherry.

Objectives: To analyze the frequency, profile and pattern of injuries among electrocution fatalities in Puducherry.

Materials and Method: The study was carried out by retrospectively collecting the 2-years data of all the medicolegal autopsy cases of electrocution related deaths brought to the Mortuary of Indira Gandhi Medical College \& Research Institute, Puducherry from January 2015 to December 2016. The data thus collected were recorded in a proforma and analyzed.

Results and Observations: Electrocution deaths accounted for $0.9 \%$ (23 cases) of all the medicolegal autopsies ( $\mathrm{n}=2607)$ conducted in our autopsy center during the study period. The highest number was observed in the age group of 41-50 years (26.1\%). Male outnumbered the female with a male female ratio of 2.83:1. Most of the victims are labourers (56.6\%) followed by housewife (17.4\%), electrician and businessman (8.7\% each respectively), official and student accounting for only $4.3 \%$ (Fig. 2). All the electrocution deaths were accidental in nature, suicidal and homicidal cases were not observed in the present study.

Conclusions: The number of electrocution deaths within the present study period are comparatively lower than other studies done in India. Proper maintenance of electrical wires and using safety measures by spreading public awareness would go a long way to bring down the fatality of electrical injuries.
\end{abstract}

Keywords: Electrocution, Accidental deaths, Electrical current, Injury.

\section{Introduction}

Any deaths occurring due to electrical shock to the body is called electrocution. The advent of electricity was taken as a boon to the civilization but use of electricity in domestic households has continued to show an increase in fatality either due to lack of public awareness or utter carelessness on the part of the general public. In today's human life electric current plays a very important role in their domestic and occupational places. Electric current can cause damage to the human body and the exact amount of damage is dependent on the type of electric current, the strength of electric current and mostly on the duration of exposure of the electric current. In developed countries, even with the significant improvement in safety of the product and proper implementation of the rules and regulations there is considerable mortality and morbidity due to electrical injuries. ${ }^{(1)}$ Deaths due to electrocution is emerging into a public health problem especially in the low income countries because of lack of awareness and poor safety issues. ${ }^{(2)}$ Indian national data on accidental deaths and suicides for calendar year 2010 \& 2011 has reported $9059 \& 8945$ electrocution deaths respectively, with a share of $2.4 \%$ of total accidental deaths. ${ }^{(3)}$ Electrocution deaths are almost always accidental and few cases are reported in the forensic work to be suicidal or homicidal in nature in India and abroad. ${ }^{(4-1)}$ Puducherry has reported the highest rate of accidental deaths as compared to the national average. This study was designed to know the frequency, victim's profile, pattern of electrical injuries \& manner of death among the study population.

\section{Materials and Method}

The study was carried out retrospectively collecting the 2-years data of all the medicolegal autopsy cases of electrocution related deaths brought to the Mortuary of Indira Gandhi Medical College \& Research Institute, Puducherry from January 2015 to December 2016. The data thus collected from the history of the cases, from the Police Papers and the medicolegal postmortem examination were recorded in a proforma and analyzed.

\section{Results and Observations}

Out of the 2607 medicolegal autopsies analyzed in the present study, electrocution deaths accounted for $0.9 \%$ of the total cases. The year-wise incidence of electrocution deaths in the present study is given in Fig. 1. The highest number of electrocution deaths was found in the year 2015 .

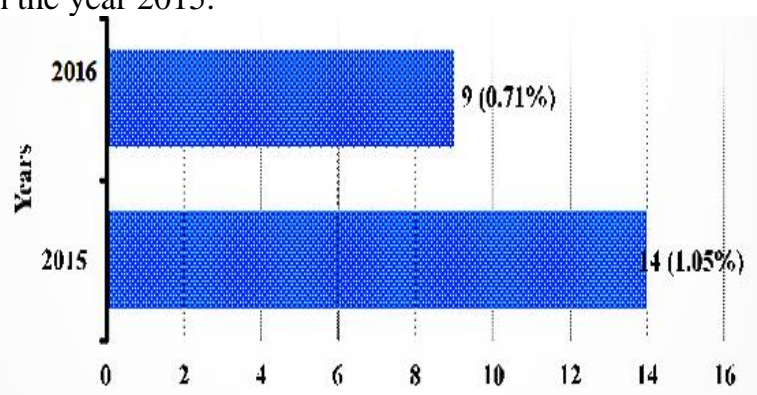

Fig. 1: Incidence of electrocution death cases

Laborers accounted for the highest number of persons (56.6\%) fatally electrocuted in our study followed by housewife $(17.4 \%)$, electrician $(8.7 \%)$ and businessman 
(8.7\%). Electricians and student accounted for $4.3 \%$ respectively (Fig. 2).

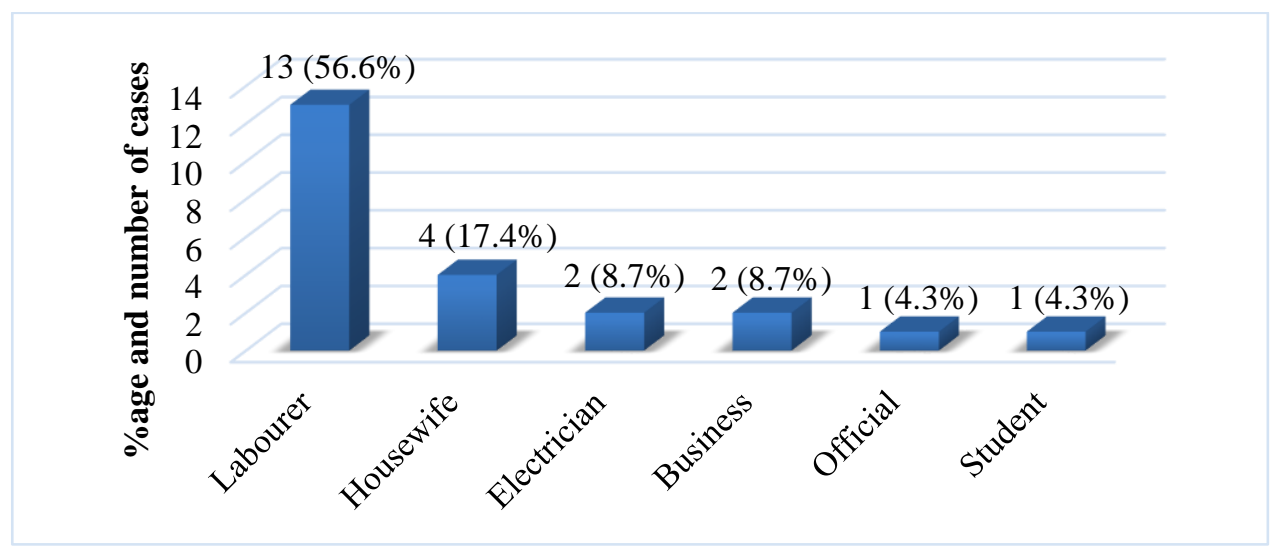

Fig. 2: Occupation of persons electrocuted

Most of the victims of electrocution were found dead in the place of occurrence (Fig. 3). In $21.73 \%$ of the cases the victims were declared dead at the hospital.

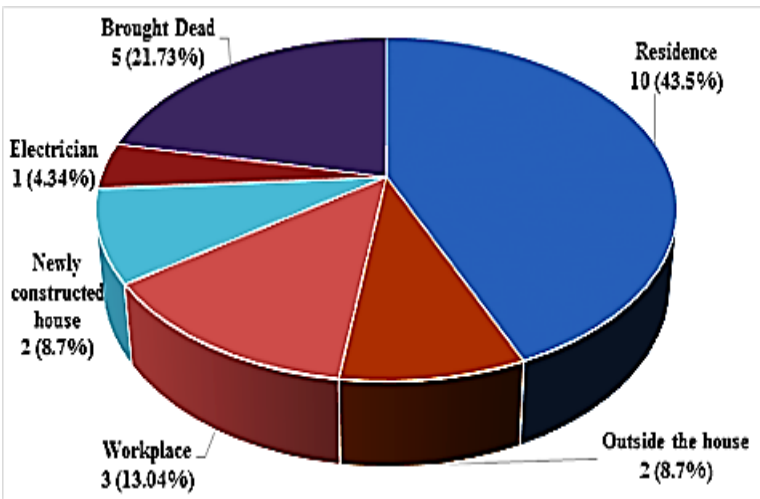

Fig. 3: Place of occurrence of electrocution

In the present series, the electrocution deaths mostly occurred during the daytime accounting for $65.22 \%$ of the cases as shown in Fig. 4.

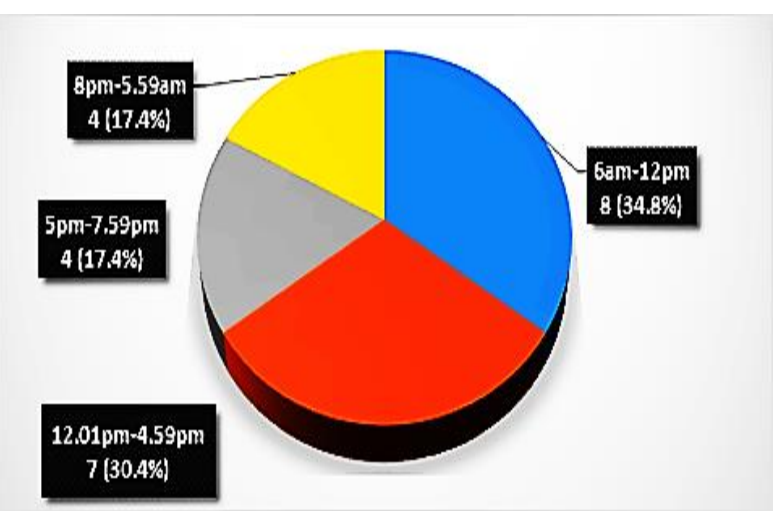

Fig. 4: Time of occurrence of electrocution

The highest number of electrocution deaths was observed during the month of August with 6 cases
(26.1\%) and September with 4 cases $(17.4 \%)$ as shown in Fig. 5.

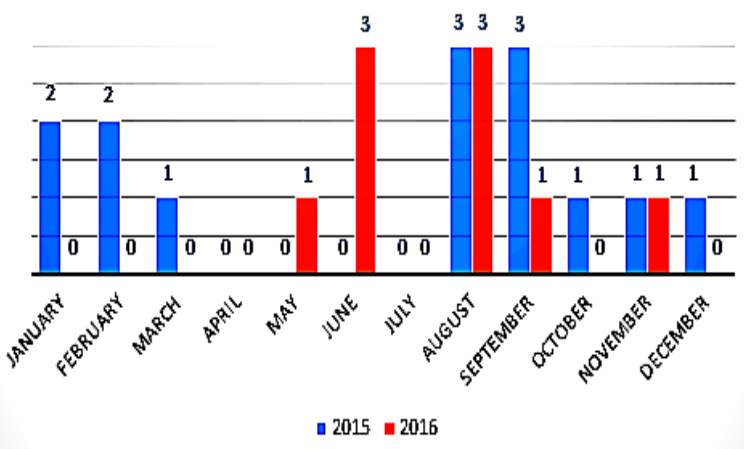

Fig. 5: Month-wise distribution of electrocution cases

Home appliances constituted the most common causative agent $(47.8 \%)$ followed by high tension wire $(34.8 \%)$ as shown in Fig. 6.

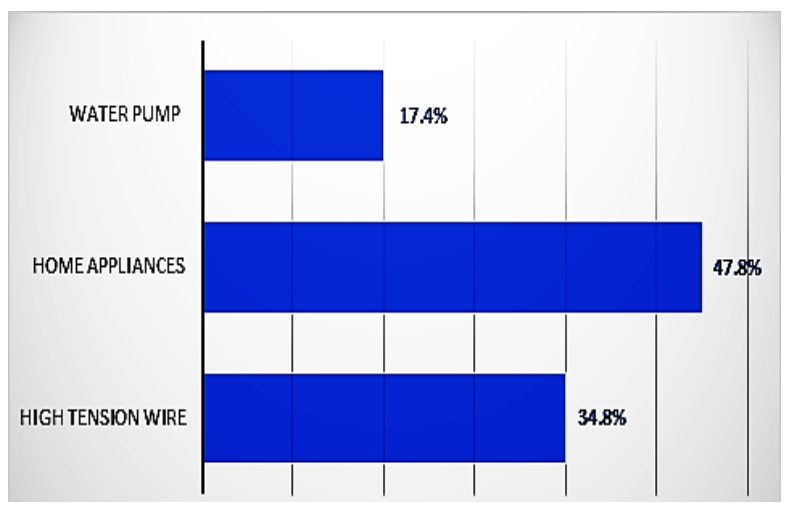

Fig. 6: Causative Agent

There was male preponderance with a male female ratio of 2.83:1. The highest number of electrocution deaths was observed in the age group of 41-50 years (26.1\%) followed by the age group of 21-30 years and 
31-40 years accounting for $17.4 \%$ each respectively

(Table 1).

Table 1: Age and Sex distribution of electrocution deaths

\begin{tabular}{|l|c|c|c|c|c|c|}
\hline Age (Yrs) & Male & \% & Female & \% & Total & \% \\
\hline $0-10$ & 0 & 0 & 0 & 0 & 0 & 0 \\
\hline $11-20$ & 2 & 11.8 & 0 & 0 & 2 & 8.7 \\
\hline $21-30$ & 4 & 23.5 & 0 & 0 & 4 & 17.4 \\
\hline $31-40$ & 4 & 23.5 & 0 & 0 & 4 & 17.4 \\
\hline $41-50$ & 4 & 23.5 & 2 & 33.3 & 6 & 26.1 \\
\hline $51-60$ & 1 & 5.9 & 2 & 33.3 & 3 & 13 \\
\hline $61-70$ & 2 & 11.8 & 1 & 16.7 & 3 & 13 \\
\hline $71-80$ & 0 & 0 & 0 & 0 & 0 & 0 \\
\hline above 80 & 0 & 0 & 1 & 16.7 & 1 & 4.4 \\
\hline Total & 17 & 100 & 6 & 100 & 23 & 100 \\
\hline
\end{tabular}

Distribution of entry and exit with site of lesion: In the present study entry wound of electrical injuries along with the corresponding exit were observed in $73.91 \%$ of the cases. No entry or exit were observed in the present series (Table 2). The most frequently involved site of entry was observed in the upper extremity $(69.56 \%)$ followed by the chest and abdomen (13.04\%). The exit wounds were mostly observed in the lower extremity (56.52\%) and there were no exit wounds in $30.43 \%$ of the cases.

Table 2: Distribution of entry and exit with site of lesion

\begin{tabular}{|l|c|c|}
\hline & $\begin{array}{c}\text { No of } \\
\text { cases }\end{array}$ & \% \\
\hline Only entry wound & 6 & 26.09 \\
\hline Entry and exit & 17 & 73.91 \\
\hline No entry and exit & 0 & 0 \\
\hline Total & 23 & 100 \\
\hline Site of lesion (entry wound) \\
\hline Upper extremity & 16 & 69.56 \\
\hline Lower extremity & 2 & 8.7 \\
\hline Head and neck & 2 & 8.7 \\
\hline Chest and abdomen & 3 & 13.04 \\
\hline No entry & 0 & 0 \\
\hline Total & 23 & 100 \\
\hline Site of lesion (Exit wound) & \multicolumn{2}{|l|}{} \\
\hline Upper extremity & 2 & 8.7 \\
\hline Lower extremity & 13 & 56.52 \\
\hline Head and neck & 0 & 0 \\
\hline Chest and abdomen & 1 & 4.35 \\
\hline No exit & 7 & 30.43 \\
\hline Total & 23 & 100 \\
\hline
\end{tabular}

\section{Discussion}

Normally electrocution is simply the result of an accident and it kills many people every year. The major reasons for accidental electrocution deaths could be due to carelessness or it could also be due to ignorance or technical defects. In the present study male constituted $73.9 \%$ of the cases which is consistent with findings of other authors. ${ }^{(9-14)}$ Male outnumbered the females in our study could be due to the fact that females normally do not associate with repair of electrical appliances as compared to their male counterparts. The incidence of electrocution deaths in our study were $0.9 \%$ which is similar to findings of Laupland et al. ${ }^{(14)}$ This findings were significantly lower compared to studies done in India ${ }^{(8,9,13,15)}$ and abroad $^{(16)}$ where they reported varying incidence of electrocution deaths of $1.98 \%, 2.2 \%$, $1.93 \%, 2.56 \%$ and $3.3 \%$ respectively. The highest number of electrocution deaths were observed in the age group of 41-50 years (26.1\%) followed by the age group of 21-30 years $(17.4 \%)$ and $31-40$ years $(17.4 \%)$. Previous researchers ${ }^{(11,12,17,18,20)}$ found $21-30$ years as the most common age group which is not in agreement with our study. In the present study electrocution deaths in the age group of 51-60 years and 61-70 years were found to be $13 \%$ of the total cases respectively. There were no minor victims of electrocution below the age group of 10 years which is consistent with the findings of Pathak et al. ${ }^{(15)}$ Gupta BD et al ${ }^{(9)}$ found $7.84 \%$ of the cases under the age of 10 years. There were 2 cases $(8.7 \%)$ of electrocution deaths under the age of 20 years (all were males) which is significantly lower than the findings of Kuhtic I et al. ${ }^{(10)}$ In our study there was one 81 -years old lady who got electrocuted when a coconut tree fell on a high tension wire and she came in contact with the live electric wire. Maximum number of victims (10 cases, $43.5 \%$ ) died at home which is in agreement with other authors $^{(9,15)}$ and 5 cases $(21.73 \%)$ were brought dead. Only 3 cases $(13.04 \%)$ died at the work place whereas other authors ${ }^{(10,12,15,18,19)}$ found higher incidence of electrocution deaths in the workplace. Many of the workers are exposed to the electrocution hazards as they often misjudge the existing dangers of live electric wires or the arcing of high-tension power cables dangling nearby. And this could be the reason for the considerable amount of morbidity and mortality seen during their working activities. Kuhtic et al ${ }^{(10)}$ found $32 \%$ of fatal electrocution among the electricians whereas in our study we found only $4.34 \%$ of the cases which is significantly lower than their findings. The electrician 
was performing his usual job at the time of being electrocuted. In regards to seasonal variations the incidence of electrocution deaths were significantly higher during the month of august and September which is in agreement with other studies. ${ }^{(12,15)}$ Majority of the incidences $(65.2 \%)$ occurred during the daytime which is consistent with the findings of other authors. ${ }^{(15)}$ The majority of cases had both the entry and the exit wound (17 cases, $73.91 \%$ ) which is consistent with the findings reported by other researchers. ${ }^{(17)}$ There were $26.09 \%$ of the cases with only entry wound which is significantly lower than the findings of other authors. ${ }^{(16)}$ In majority of the cases $(69.56 \%)$ of entry wounds the upper extremity was the most common body part involved and $56.52 \%$ of exit wounds were observed in the lower extremity which is consistent with the findings of other researchers. ${ }^{8,9,12,15,19)}$ Lower extremity and head \& neck accounted for $8.7 \%$ of the cases respectively for the entry wound which is significantly lower than the study done by Guntheti et al ${ }^{(20)}$ where they found $37.50 \%$ of entry wounds in the head and neck. Chest and abdomen was involved in $13.04 \%$ of the cases of the entry wound. Low-voltage cases accounted for the majority of the cases of fatal electrocution in our study with $65.2 \%$ of the cases which is in contrast to Ragui $\mathrm{S}$ et al ${ }^{(17)}$ where the majority of the cases were due to high tension electrocution.

\section{Conclusion}

Electrocution deaths were found to be much lower among all the medicolegal deaths in the present study compared to studies done by other authors. Most of the cases are due to accidental touching of live electric wire or accidental fall on live electric wire on the victims. Proper maintenance of electrical wires and using safety measures by spreading public awareness would go a long way to bring down the fatality of electrical injuries.

\section{References}

1. Koumbourlis AC. Electrical injuries. Critical care Medicine 2002;30:424-30.

2. Mashreky SR, Rahman A, Khan TF, Svanstrom L, Rahman F. Epidemiology of Childhood electrocution in Bangladesh: findings of national survey. Burns 2010;36:1092-5.

3. Accidental deaths and Suicides in India 2011. National Crime Records Bureau. Ministry of Home Affairs. Available at http://ncrb.nic.in/CD-ADSI2011/ADSI2011\%20REPORT.pdf. accessed on 24 June 2014.

4. Shaha KK, Joe AE. Electrocution-related mortality: A retrospective review of 118 deaths in Coimbatore, India, Between January 2002 and December 2006. Med Sci Law 2010 Apr;50 (2):72-4.

5. Das S, Patra AP, Shaha KK, Sistla SC, Jena MK. Highvoltage suicidal electrocution with multiple exit wounds. Am JForensic Med Pathol. 2013;34(1):34-37.

6. Jambure MP, Tandle RM, Zine KU. Electrocution method to conceal homicide A rare case report. J Indian Acad For Med. 2012;34(1):92-94.
7. Fernando LS. Suicide by electrocution. Med Sci Law. 1990;30:219-20.

8. Rautji R, Rudra A, Behara C, Dogra TD. Electrocution in South Delhi; A retrospective study. Med Sci Law. 2003;43(4):350-2.

9. Gupta BD, Mehta RA, Trangadia MM. Profile of deaths due to electrocution: a retrospective study. J Indian Acad Forensic Med. 2012;34(1):13-15.

10. Kuhtic I, Bakovic M, Mayer D, Strinovic D, Petrovecki V. Electrical mark in electrocution deaths - 120 -years study. The Open Forensic Sci J. 2012;(5):23-27.

11. Shrigiriwar M, Bardale R, Dixit PG. Electrocution: a six year study of electrical fatalities. J Indian Acad Forensic Med. 2007;29(2):50-53.

12. Kumar S, Verma AK, Singh US. Electrocution-related mortality in northern India-a 5-year retrospective study. Egyptian J For Sci. 2014;4(1):1-6.

13. Chakraborty PN, Das P. Epidemiological study of fatal electrocution cases-a mortuary based 3-years retrospective study. J Evolution Med Dent Sci. 2017;6(9):665-67.

14. Laupland KB, Korbeek JB, Finlay C, Kirkpatrick AW, Hameed SM. Population based study of severe trauma due to electrocution in the Calgary Health Region 19962002. Can J Surg. 2005;(48):289-92.

15. Pathak AK, Disania NL. Pattern and seasonal variations in death due to electrocution: a retrospective study. Int J Med Sci Public Health 2015;4(1):19-22.

16. Tirasci Y, Goren S, Subasi M, Gruken F. Electrocution related mortality: a review of 123 deaths in Diyarbakir, Turkey between 1996 and 2002. Tohoku J Exp Med. 2006;(208):141-45.

17. Ragui S, Meera Th, Singh KP, Devi PM, Devi AS. A study of electrocution deaths in Manipur. J Med Soc. 2017;27(2):124-26.

18. Shaha KK, Joe AE. Electrocution related mortality: a retrospective review of 118 deaths in Coimbatore India between Jan 2002 and December 2006. Med Sci Law 2010;50:72-4.

19. Sheikhazadi A, Kiani M, Ghadyani MH. Electrocutionrelated mortality: a survey of 295 deaths in Tehran, Iran between 2002 and 2006. Am J Forensic Med Pathol. 2010;31(1):42-5.

20. Guntheti BK, Khaja S, Singh UP. Pattern of injuries due to electric current. J Indian Acad Forensic Med. 2012;34(1):44-48. 